\title{
Physiological and growth responses of sour cherry (Prunus cerasus L.) plants subjected to short-term salinity stress
}

\author{
Ioannis E. Papadakis ${ }^{1,2,}$, Georgia Veneti ${ }^{2}$, Christos Chatzissavvidis ${ }^{2,3}$, Ioannis Therios ${ }^{2}$ \\ ${ }^{1}$ Laboratory of Pomology, Department of Crop Science, Agricultural University of Athens, Iera Odos 75, 11855 Athens, \\ Greece \\ ${ }^{2}$ Laboratory of Pomology, School of Agriculture, Aristotle University, 54124 Thessaloniki, Greece \\ ${ }^{3}$ Department of Agricultural Development, Democritus University of Thrace, 68200 Orestiada, Greece
}

\begin{abstract}
The gradual response of CAB-6P sour cherry (Prunus cerasus L.) plants to NaCl-induced salinity stress $(60 \mathrm{mM} \mathrm{NaCl})$ was investigated in a short-term hydroponic experiment, based on parameters relating to the growth, water relations, chlorophyll and mineral nutrition. The results showed that CAB-6P plants are very sensitive to salinity stress because their growth and leaf chlorophyll concentration were both affected negatively from the $3^{\text {rd }}$ and $5^{\text {th }}$ day, respectively, after incurring salinity stress. Since root growth was suppressed more severely than shoot growth, the shoot to root ratio was significantly increased under saline conditions. The concentrations of $\mathrm{Na}$ in leaves and stem of $\mathrm{NaCl}$-treated plants were much lower than those measured in roots, suggesting $\mathrm{Na}$ exclusion mechanism from the shoot. The opposite trend was observed for $\mathrm{Cl}$, indicating $\mathrm{Cl}$ inclusion mechanism to leaves. As regards the concentrations of $\mathrm{Ca}, \mathrm{Mg}, \mathrm{P}, \mathrm{K}, \mathrm{Na}, \mathrm{Fe}, \mathrm{Zn}$ and $\mathrm{Mn}$, they were not changed in higher salinity conditions, apart from $\mathrm{K}$, concentrations of which in leaves and roots were significantly increased and decreased, respectively ( $\mathrm{K}$ translocation to leaves). Salinity further reduced K/Na ratio in root and stem as well as leaf water and osmotic potentials, whereas leaves of control and NaCl-treated plants presented similar turgor potential and $\mathrm{K} / \mathrm{Na}$ ratio. These data add very important information to our knowledge about the physiological events occurring in sour cherry plants after even short-term exposure to salinity.
\end{abstract}

Keywords: chlorophyll, CAB-6P rootstock, $\mathrm{Cl}$ inclusion, ion concentrations, Na exclusion, osmotic adjustment, water relations

\section{Introduction}

An excess of soil salinity affects the performance of hundreds of crop species worldwide and may be particularly deleterious to most fruit tree crops, which are usually saltsensitive (Ziska et al. 1990). It is also well documented that various Prunus species are included in the group of salt sensitive species (Andreu et al. 2011). Although, there are many published papers dealing with the effects of salinity on growth, antioxidants, photosynthesis, nutritional status and several other parameters of Prunus species (Ziska et al. 1990, Papadakis et al. 2007, Chatzissavvidis et al. 2008, Andreu et al. 2011), there are no detailed studies regarding the changes and/or possible adaptations occurring just after exposure to saline environments. Such data would add valuable informa- tion to our knowledge about the initial events that take place during the exposure of fruit trees to salinity. In fact, salinity is not a real problem in the main world's regions where sweet and sour cherries are traditionally cultivated, since these areas have usually high levels of rainfall and, therefore, high availability of good quality irrigation water. Nowadays, however, there are some new low-chill cherry varieties, and, of course, more will be produced in the future. These new varieties can be cultivated in warmer/more arid areas of the world, including lowlands and coastal ares, where, at least during the summer months, irrigation water of poor quality containing high levels of salts is commonly used. According to Tattini et al. (1995), the maintenance of plant growth and

*Corresponding author, e-mail: papadakis@aua.gr 
productivity is very important for perennial crops that are subjected to transitional periods of saline conditions. On the other hand, rootstocks possess a critical role for the sustainable cultivation of plants, and are a tool with which farmers can alleviate salinity and/or other environmental constraints in their orchards (Papadakis 2016). Therefore, the current study aimed to investigate the growth and physiological responses (plant growth, chlorophyll concentration, water relations and nutrient status) of the well-known sour cherry genotype CAB-6P, which is widely used as a rootstock for both sour and sweet cherry cultivars, under salt stress.

\section{Materials and methods}

One-year-old, uniform, self-rooted plants of the clone CAB-6P (Prunus cerasus L.) were transplanted in black plastic bags filled with $3 \mathrm{~L}$ of a sand/perlite mixture (50/50, v/v). In fact, the use of small-asexually propagated plants of about $25 \mathrm{~cm}$ in height was aimed at determining even the initial, tiny changes caused by the salinity stress. The plants were irrigated with good quality tap water for seven weeks before $\mathrm{NaCl}$ treatment was imposed. Afterwards, the plants were irrigated, thrice a week, with $300 \mathrm{~mL}$ of the well-known Hoagland nutrient solution No 2 (Hoagland and Arnon 1950) containing either 0 or $60 \mathrm{mM} \mathrm{NaCl}$. The concentration of 60 $\mathrm{mM} \mathrm{NaCl}$ is within the range of $\mathrm{NaCl}$ concentrations usually observed in irrigation waters of the Mediterranean basin (Flowers 1999). The experiment was carried out in a glasshouse, with temperatures ranging between 18 and $30^{\circ} \mathrm{C}$, and lasted 13 days. Three plants per treatment were randomly selected, every two days after salinity imposition, for mea- suring water $\left(\Psi_{\mathrm{w}}\right)$, osmotic $\left(\Psi_{\pi}\right)$ and turgor $\left(\Psi_{\mathrm{p}}\right)$ potentials as well as chlorophyll concentration in fully expanded apical leaves. Finally, the plants were separated into root, stem and leaves. After estimating the fresh and dry weights of all these plant portions, they were further analyzed for $\mathrm{Na}, \mathrm{Cl}$, $\mathrm{K}, \mathrm{N}, \mathrm{P}, \mathrm{Ca}, \mathrm{Mg}, \mathrm{Fe}, \mathrm{Mn}$ and $\mathrm{Zn}$. All the methods, procedures and equipments used for the aforementioned measurements and determinations have already been described in our previously published paper (Papadakis et al. 2007).

The experimental design was completely randomized. In all, 36 plants were used: 18 were controls $(0 \mathrm{mM} \mathrm{NaCl})$ and 18 were $\mathrm{NaCl}$-treated $(60 \mathrm{mM} \mathrm{NaCl})$. From the third day $\left(3^{\text {rd }}\right.$ day) after salinity imposition until the last day of experimentation ( $13^{\text {th }}$ day), 3 plants from each treatment were harvested every two days, i.e., 2 treatments (control, salinity) $\times 3$ plants per sampling day and treatment $\times 6$ sampling days $\left(3^{\text {rd }}, 5^{\text {th }}, 7^{\text {th }}, 9^{\text {th }}, 11^{\text {th }}\right.$ and $\left.13^{\text {th }}\right)$. For each parameter and sampling day, means of control and $\mathrm{NaCl}$-treated plants were compared with each other using the Student's t-test $(\mathrm{P} \leq 0.05)$.

\section{Results and discussion}

Salinity reduced the weights of leaves (Fig. 1A), stems and roots (Fig. 1B), and therefore the total weight of $\mathrm{CAB}$ $6 \mathrm{P}$ plants (Fig. 1C), even from the $3^{\text {rd }}$ day of the experiment. Furthermore, $\mathrm{NaCl}$-treated plants presented significantly higher values of shoot to root ratio (on a dry weight basis) than the control plants, from the $7^{\text {th }}$ day of the experiment and thereafter (Fig. 1D). A decline in dry weight of leaves and stems was also observed in two cherry cultivars
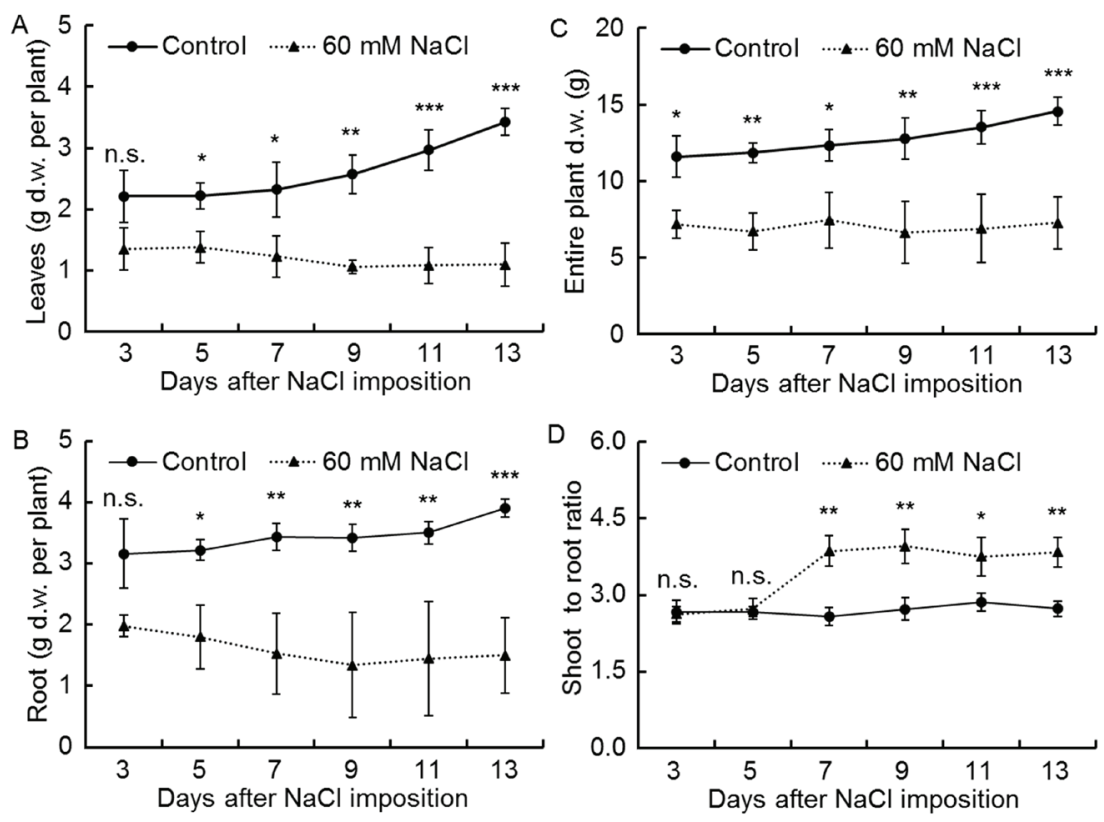

Fig. 1. Dry weight (d.w.) of leaves (A), root (B), and entire plant (C); shoot to root ratio (D) of control (0 mM NaCl) and salinity-treated $(60 \mathrm{mM} \mathrm{NaCl})$ Prunus cerasus plants at different days $(3,5,7,9,11$ or 13) after $\mathrm{NaCl}$ imposition. Results are expressed as mean values \pm SE. For each parameter and day after salt stress imposition, asterisks indicate significant differences between control and NaCl-treated plants, at $\mathrm{P} \leq 0.05\left(^{*}\right), \mathrm{P} \leq 0.010\left(^{* *}\right)$ or $\mathrm{P} \leq 0.001\left(^{* * *}\right)$; n.s. indicates non-significant differences. 
subjected to salinity conditions (Papadakis et al. 2007). The osmotic stress leads to an instant decline in cell expansion of young roots and leaves, causing stomatal closure as well. Enhanced resistance to osmotic stress would be beneficial for leaf growth and stomatal conductance, but the resulting increased leaf area would be productive only if plants had adequate soil water (Munns and Tester 2008), such as under the current experimental conditions. The latter consideration could possibly explain the fact that the root growth of CAB-6P plants was inhibited by salinity to a greater extent than shoot growth (increased values of shoot/root ratio). In other words, the root of CAB-6P plants is more sensitive to salinity than the shoot, at least in the first two weeks after the imposition of $\mathrm{NaCl}$ stress. This finding is not in accordance with the results of other researchers working with many different crops, like tomato (Albacete et al. 2008). More specifically, the shoot to root ratio in salt-treated tomato plants was decreased (an important adaptive response) due to the rapid inhibition of shoot growth (which limits plant productivity) while root growth was maintained (Albacete et al. 2008). The reduction of shoot to root ratio is one of the most usual symptoms of plants subjected to salinity stress resulting in improvement of water use efficiency within the plant. It was suggested that the plants subjected to high salinity save water by minimizing their shoot growth and by keeping a normal water status for growth (Sohan et al. 1999). In contrast to these reports, our results are in agreement with those stated by Bernstein and coworkers (2004), who found that the shoot growth of avocado plants was less sensitive to salinity than root growth. The strong inhibition of root growth is expected to affect the entire plant and thus the root growth could be considered an important criterion for rootstocks' tolerance to $\mathrm{NaCl}$ (Bernstein et al. 2004). Overall, since the root growth of CAB-6P plants was dramatically affected by salinity, even from the first days of the current short-term experiment, the use of CAB-6P as rootstock has to be avoided when sweet or sour cherry varieties are going to be cultivated in areas having low quality irrigation water.

Genotypes with high capabilities to control $\mathrm{Cl}$ and $\mathrm{Na}$ absorption by roots and/or $\mathrm{Cl}$ and $\mathrm{Na}$ movement from roots to stems and especially to leaves, present high tolerance to salinity (Storey and Walker 1999). Ion exclusion and compartmentation at the root level regulates ion concentration in the xylem sap, preventing thus the accumulation of potentially toxic ions in the aboveground plant parts. This mechanism is effective at levels of salinity up to $50 \mathrm{mM} \mathrm{NaCl}$, but it considerably impedes plant growth. The accumulation of $\mathrm{Na}$ in roots provides a mechanism for many crops, such as olive, to cope with salinity in the root zone and may indicate the existence of an inhibitory mechanism of Na transport to leaves (Chartzoulakis 2005). In the current study, the concentrations of $\mathrm{Na}$ in the shoots (leaves and stems) of $\mathrm{NaCl}$-treated plants (Fig. 2A-B) were much lower than those in the roots (Fig. 2C). Moreover, lower Na concentrations were found in leaves (Fig. 2A) than in stems (Fig. 2B). Therefore, CAB-6P sour cherry plants must have had the capability to control the absorption of $\mathrm{Na}$ and/or its transport to stems and leaves. In general, $\mathrm{Na}$ exclusion from the shoot has often been reported as a crucial mechanism for plants to tolerate high salinity (Jha et al. 2010). On the other hand, the increase of $\mathrm{Cl}$ concentration in the $\mathrm{NaCl}$-treated plants was simultaneous in all plant parts (leaves, stems and roots), from the $9^{\text {th }}$ day of $\mathrm{NaCl}$ imposition and thereafter (Figs. 2DF). Furthermore, higher $\mathrm{Cl}$ concentrations were determined in leaves of NaCl-treated plants (Fig. 2D) than in the stems (Fig. 2E) and roots (Fig. 2F), especially after the $11^{\text {th }}$ day of the experiment, which indicates that a $\mathrm{Cl}$ inclusion mechanism (export to leaves) was implicated. Therefore, it could be concluded that CAB-6P sour cherry plants are very sensitive to salinity, since the mechanism controlling (restricting) $\mathrm{Cl}$ absorption by roots collapsed quickly (from the $9^{\text {th }}$ day of plants' exposure to salinity and thereafter), although the concentration of $\mathrm{NaCl}(60 \mathrm{mM})$ in the nutrient solution was relatively low. In other words, a high susceptibility of $\mathrm{CAB}-6 \mathrm{P}$ plants to $\mathrm{Cl}$ absorption when they were subjected to saline conditions was revealed. Leaf $\mathrm{Cl}$ concentration has been commonly used as a reliable criterion for rating plant species according to their efficiency under saline conditions (Antcliff et al. 1983, Storey and Walker 1999). In short, the sensitivity of sour cherry plants to salinity is closely correlated with $\mathrm{Cl}$ concentration in various plant parts (mainly in the leaves). This criterion could be applied for future screening studies of other sour cherry genotypes for their relative sensitivity to saline conditions.

In a previous study where the effects of $\mathrm{NaCl}$ in the mineral nutrition of two sweet cherry varieties were investigated, it was found that the concentrations of all nutrients, except for $\mathrm{N}$ and $\mathrm{Mg}$, in leaves, stems and roots of both cultivars were altered under the treatment of $50 \mathrm{mM} \mathrm{NaCl}$. In addition, the root was the main plant organ whose nutrient content was mostly affected by $\mathrm{NaCl}$, probably because it is the plant part that salts enter first (Papadakis et al. 2007). Based on the concentrations of various mineral elements (N, P, Mg, $\mathrm{Ca}, \mathrm{Mn}, \mathrm{Zn}$ and $\mathrm{Fe}$ ) determined in roots, stems and leaves of CAB-6P plants, no one significant difference was found between control and $\mathrm{NaCl}$-treated plants (data not shown). This finding could be mainly ascribed to the short duration of the salinity stress imposition which was not enough to affect the overall nutritional status of sour cherry plants. The only exception was potassium $(\mathrm{K})$ which was strongly affected by $\mathrm{NaCl}$ (Fig. 2G-I). Liu and van Staden (2001) suggested that a constant or increased level of internal $\mathrm{K}$ is of major importance for a better response of entire plants and/or plant tissues to salinity stress. In the current study, although control and NaCl-treated CAB-6P plants had similar concentrations of $\mathrm{K}$ in their stems (Fig. $2 \mathrm{H}$ ), salinity decreased or increased $\mathrm{K}$ concentrations in roots (at $11^{\text {th }}$ and $13^{\text {th }}$ day) (Fig. 2I) and leaves (at $13^{\text {th }}$ day) (Fig. 2G), respectively. A possible explanation could be the existence of a mechanism that removes $\mathrm{K}$ from roots to aerial plant parts, especially to leaves (Romero and Marañón 1994). Furthermore, the relatively high salt tolerance is usually correlated with relatively high values of $\mathrm{K} / \mathrm{Na}$ ratio in plant tissues (Liu and van Staden 2001). Giri et al. (2007) experimenting with the mycorrhizal 

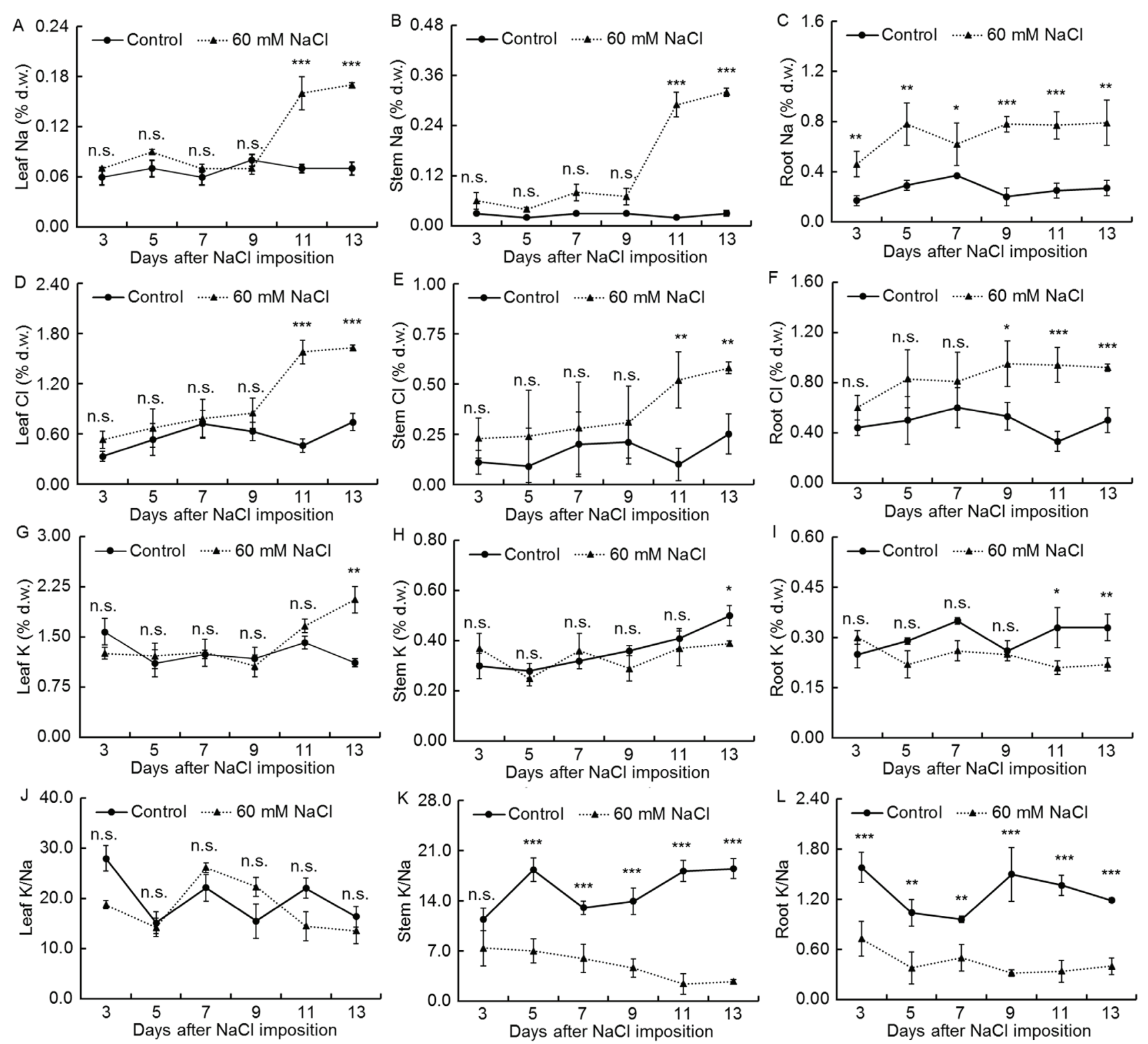

Fig. 2. Concentrations of $\mathrm{Na}(\mathrm{A}, \mathrm{B}, \mathrm{C}), \mathrm{Cl}(\mathrm{D}, \mathrm{E}, \mathrm{F})$ and $\mathrm{K}(\mathrm{G}, \mathrm{H}, \mathrm{I})$ in leaves $(\mathrm{A}, \mathrm{D}, \mathrm{G})$, stem $(\mathrm{B}, \mathrm{E}, \mathrm{H})$ and $\operatorname{root}(\mathrm{C}, \mathrm{F}, \mathrm{I})$; K/Na ratio in leaves $(\mathrm{J})$, stem $(\mathrm{K})$ and root $(\mathrm{L})$ determined in control $(0 \mathrm{mM} \mathrm{NaCl})$ and salinity-treated $(60 \mathrm{mM} \mathrm{NaCl})$ Prunus cerasus plants at different days $(3,5,7,9,11$ or 13$)$ after $\mathrm{NaCl}$ imposition. Results are expressed as mean values $\pm \mathrm{SE}$. For each parameter and day after salt stress imposition, asterisks indicate significant differences between control and $\mathrm{NaCl}$-treated plants, at $\mathrm{P} \leq 0.05\left(^{*}\right), \mathrm{P} \leq 0.010\left(^{* *}\right)$ or $\mathrm{P} \leq 0.001\left(^{(* *}\right)$; n.s. indicates non-significant differences.

Acacia nilotica under saline conditions found that elevated $\mathrm{K} / \mathrm{Na}$ ratios in root and shoot may prevent $\mathrm{K}$-mediated enzymatic processess from disruption. In contrast, our data have shown that stem and root $\mathrm{K} / \mathrm{Na}$ ratios in $\mathrm{NaCl}$-treated plants were much lower than those of control plants, from the $3^{\text {rd }}$ (root) or $5^{\text {th }}$ (stem) day after salinity stress imposition (Figs. 2K-L). Regarding the leaf K/Na ratio (Fig. 2J), no significant difference between control and salinity stressed plants during the experiment was found. Moreover, the K/Na ratio in leaves of CAB-6P plants (Fig. 2J) was much higher than in stems (Fig. 2K) and roots (Fig. 2L), irrespective of the $\mathrm{NaCl}$ treatment and/or sampling day. This latter finding was due to the relatively high concentrations of $\mathrm{K}$ and low concentrations of $\mathrm{Na}$ found in $\mathrm{CAB}-6 \mathrm{P}$ leaves, a fact that was governed by the parallel existence of an Na-exclusion mechanism from the shoot and a K-inclusion (transport) mechanism to the leaves. In other words, salt-treated CAB-6P plants were capable of maintaining an appropriate (similar to that of control plants) leaf K-to-Na ratio, probably for protecting the most actively growing portion of plants (leaves). In accordance with the results of other studies (Chartzoulakis 2005, and references therein), the diminution of $\mathrm{K}$ concentrations in roots of $\mathrm{NaCl}$-treated plants, which resulted in too low $\mathrm{K} / \mathrm{Na}$ ratios, may also provide a mechanism by which $\mathrm{CAB}-6 \mathrm{P}$ plants achieved ionic balance following the high $\mathrm{Na}$ absorption by their roots. 
In a previous in-vitro experiment with $\mathrm{CAB}-6 \mathrm{P}$ explants treated with $60 \mathrm{mM} \mathrm{NaCl}$, one of the main effects of the high leaf $\mathrm{Cl}$ concentration (4.2-5.6 \% d.w.) was the decline in chlorophyll concentration of leaves (Chatzissavvidis et al. 2008). Similarly, in another study with Prunus salicina, leaf chlorophyll concentration decreased when leaf chloride exceeded $0.25 \mathrm{~mol} \mathrm{~kg}^{-1}$ d.w. (about $0.9 \%$ d.w.) (Ziska et al. 1990). In the current short-term study, the total leaf chlorophyll concentration was also reduced by the salinity, from the $5^{\text {th }}$ day of the experiment and thereafter (Fig. 3A). However, this decrease in leaf chlorophyll could not mainly be ascribed to either the toxic effects of accumulated $\mathrm{Na}$ (ranged between $0.07 \%$ d.w. $-5^{\text {th }}$ day- and $0.19 \%$ d.w. $-13^{\text {th }}$ day-) and $\mathrm{Cl}$ (ranged between $0.67 \%$ d.w. $-5^{\text {th }}$ day- and $1.63 \%$ d.w. $-13^{\text {th }}$ day-) ions in leaves or to deficiencies of other mineral nutrients (similar concentrations were found in salt-treated and control plants). Alternately, it might rather have been due to $\mathrm{NaCl}$-induced changes in the overall physiological status of plants (low water potential, possible closure of stomata, a decrease of photosynthetic performance, oxidative damages, etc.). The lower values of water (Fig. 3B) and osmotic (Fig. 3C) potentials found in the leaves of $\mathrm{NaCl}$-treated sour cherry plants, compared with those of control plants, resulted in turgor potential values (Fig. 3D) similar to those of control plants. This latter observation in combination with the increased concentrations of $\mathrm{Na}, \mathrm{K}$ and $\mathrm{Cl}$ found in leaves of $\mathrm{NaCl}$-treated plants leads to the conclusion that CAB-6P plants are osmoregulated by the accumulation of inorganic ions. In any case, however, the possible contribution of some compatible solutes in the osmotic adjustment of sour cherry plants could not be excluded since relevant measurements were not carried out. Therefore, since (a) it is nearly impossible for a cell to adjust osmotically using only inorganic ions, and (b) Prunus species produce and accumulate significant amounts of sorbitol and proline under dehydration stress (Jiménez et al. 2013, Zrig et al. 2016), which may work as a membrane and as metabolism stabilizers and antioxidants, the contribution of soluble carbohydrates and other compatible organic solutes in the osmoregulation of sour cherry plants subjected to salinity stress has to be further investigated.

Overall, CAB-6P sour cherry plants are very sensitive to salinity stress since their growth and leaf chlorophyll concentration were both affected negatively from the $3^{\text {rd }}$ and $5^{\text {th }}$ day, respectively, after the imposition of salinity. Moreover, the results of this short-term study revealed some interesting responses of sour cherry plants under saline conditions. Firstly, their root growth was affected more than their shoot growth (dry weight basis). Secondly, an Na-exclusion mechanism from the shoot (stems and leaves) was found to take place. Thirdly, the existence of $\mathrm{Cl}$ - and $\mathrm{K}$-inclusion mechanisms to leaves were also a fact. Therefore, CAB-6P plants were able to control the uptake of $\mathrm{Na}$ and/or its transport from roots to leaves more appropriately than they could $\mathrm{Cl}$. Fourthly, plants had the capability of osmoregulation, a fact that apparently limited the detrimental effects of salinity. Finally, from a pomological point of view, the use of the CAB-6P sour cherry clone as rootstock for sweet and sour cherry plantations has to be avoided in areas having low quality irrigation water, even if salinity is just a short-term-seasonal problem.
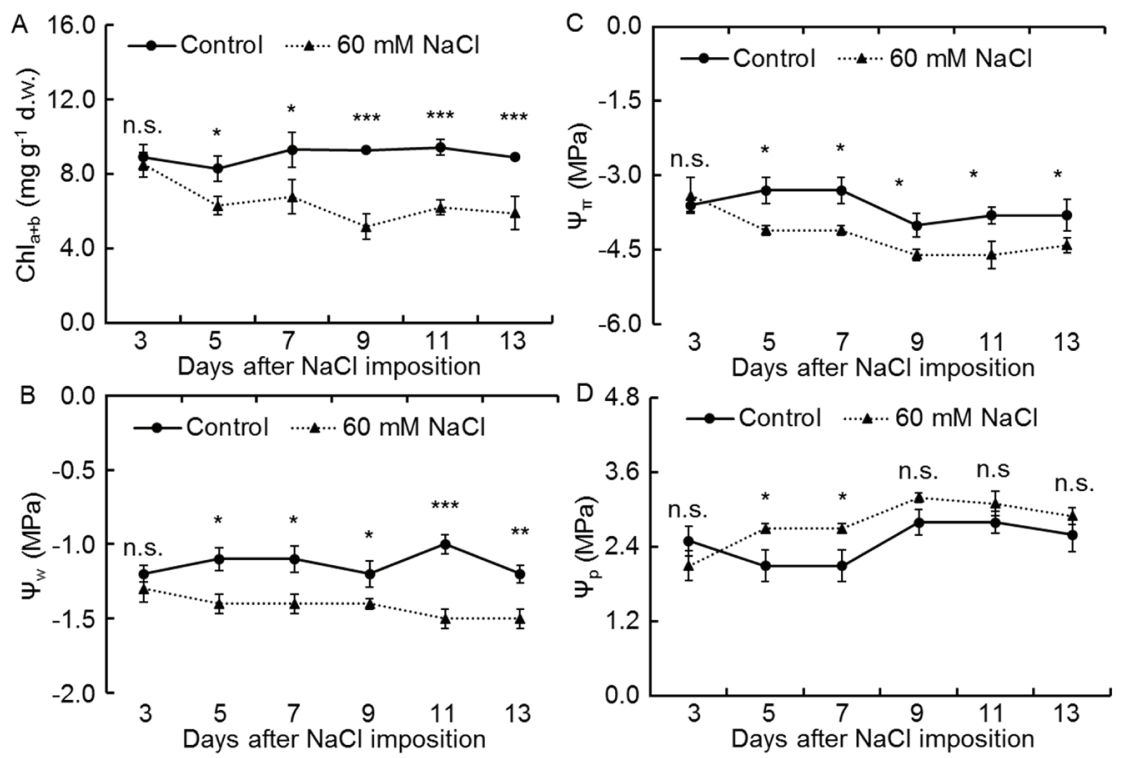

Fig. 3. Total leaf chlorophyll concentration (A); leaf water potential $\left(\Psi_{w}\right)(B)$, osmotic potential $\left(\Psi_{\pi}\right)(C)$ and turgor potential $\left(\Psi_{\mathrm{p}}\right)(\mathrm{D})$ determined in control $(0 \mathrm{mM} \mathrm{NaCl})$ and salinity-treated $(60 \mathrm{mM} \mathrm{NaCl})$ Prunus cerasus plants at different days $(3,5,7,9,11$ or 13$)$ after $\mathrm{NaCl}$ imposition. Results are expressed as mean values \pm SE. For each parameter and day after salt stress imposition, asterisks indicate significant differences between control and NaCl-treated plants, at $\mathrm{P} \leq 0.05\left(^{*}\right), \mathrm{P} \leq 0.010\left(^{(*}\right)$ or $\mathrm{P} \leq 0.001\left({ }^{* *}\right)$; n.s. indicates non-significant differences. 


\section{References}

Albacete, A., Ghanem, M. E., Martínez-Andújar, C., Acosta, M., Sánchez-Bravo, J., Martínez, V., Lutts, S., Dodd, I. C., PérezAlfocea, F., 2008: Hormonal changes in relation to biomass partitioning and shoot growth impairment in salinized tomato (Solanum lycopersicum L.) plants. Journal of Experimental Botany 59, 4119-4131.

Andreu, P., Arbeloa, A., Lorente, P., Marín, J. A., 2011: Early detection of salt stress tolerance of Prunus rootstocks by excised root culture. HortScience 46, 80-85.

Antcliff, A. J., Newman, H. P., Barrett, H. C., 1983: Variation in chloride accumulation in some American species of grapevine. Vitis 22, 357-362.

Bernstein, N., Meiri, A., Zilberstaine, M., 2004: Root growth of avocado is more sensitive to salinity than shoot growth. Journal of the American Society for Horticultural Science 129, $188-192$.

Chartzoulakis, K. S., 2005: Salinity and olive: Growth, salt tolerance, photosynthesis and yield. Agricultural Water Management 78, 108-121.

Chatzissavvidis, C., Veneti, G., Papadakis, I., Therios, I., 2008: Effect of $\mathrm{NaCl}$ and $\mathrm{CaCl}_{2}$ on the antioxidant mechanism of leaves and stems of the rootstock CAB-6P (Prunus cerasus L.) under in vitro conditions. Plant Cell Tissue and Organ Culture 95, 37-45.

Flowers, T. J., 1999: Salinisation and horticultural production. Scientia Horticulturae 78, 1-4.

Giri, B., Kapoor, R., Mukerji, K. G., 2007: Improved tolerance of Acacia nilotica to salt stress by arbuscular mycorrhiza, Glomus fasciculatum may be partly related to elevated $\mathrm{K} / \mathrm{Na}$ ratios in root and shoot tissues. Microbial Ecology 54, 753-760.

Hoagland, D. R., Arnon, D. I., 1950: The water-culture method for growing plants without soil. Circular. California Agricultural Experiment Station, 347.

Jha, D., Shirley, N., Tester, M., Roy, S. J., 2010: Variation in salinity tolerance and shoot sodium accumulation in Arabidopsis ecotypes linked to differences in the natural expression levels of transporters involved in sodium transport. Plant, Cell and Environment 33, 793-804.
Jiménez, S., Dridi, J., Gutiérrez, D., Moret, D., Irigoyen, J. J., Moreno, M. A., Gogorcena, Y., 2013: Physiological, biochemical and molecular responses in four Prunus rootstocks submitted to drought stress. Tree Physiology 33, 1061-1075.

Liu, T., van Staden, J, 2001: Growth rate, water relations and ion accumulation of soybean callus lines differing in salinity tolerance under salinity stress and its subsequent relief. Plant Growth Regulation 34, 277-285.

Munns, R., Tester, M., 2008: Mechanisms of salinity tolerance. Annual Review of Plant Biology 59, 651-681.

Papadakis, I. E., Veneti, G., Chatzissavvidis, C., Sotiropoulos, T. E., Dimassi, K. N., Therios, I. N., 2007: Growth, mineral composition, leaf chlorophyll and water relationships of two cherry varieties under $\mathrm{NaCl}$-induced salinity stress. Soil Science and Plant Nutrition 53, 252-258.

Papadakis, I. E., 2016: The timeless contribution of rootstocks towards successful horticultural farming: from ancient times to the climate change era. American Journal of Agricultural and Biological Sciences 11, 137-141.

Romero, J. M., Marañón, T., 1994: Long-term responses of Melilotus segetalis to salinity. I. Growth and partitioning. Plant, Cell and Environment 17, 1243-1248.

Sohan, D., Jasoni, R., Zajicek, J., 1999: Plant-water relations of $\mathrm{NaCl}$ and calcium-treated sunflower plants. Environmental and Experimental Botany 42, 105-111.

Storey, R., Walker, R. R., 1999: Citrus and salinity. Scientia Horticulturae 78, 39-81.

Tattini, M., Gucci, R., Coradeschi, M. A., Ponzio, C., Everard, J. D., 1995: Growth, gas exchange and ion content in Olea europaea plants during salinity stress and subsequent relief. Physiologia Plantarum 95, 203-210.

Ziska, L. H., Seemann, J. R., DeJong, T. M., 1990: Salinity induced limitations on photosynthesis in Prunus salicina, a deciduous tree species. Plant Physiology 93, 864-870.

Zrig, A., Mohamed, H. B., Tounekti, T., Khemira, H., Serrano, M., Valero, D., Vadel, A. M., 2016: Effect of rootstock on salinity tolerance of sweet almond (cv. Mazzetto). South African Journal of Botany 102, 50-59. 